\title{
Prevalence, risk factors and associated adverse pregnancy outcomes of anaemia in Chinese pregnant women: a multicentre retrospective study
}

\author{
Li Lin ${ }^{1}$, Yumei Wei ${ }^{1}$, Weiwei Zhu², Chen Wang ${ }^{1}$, Rina Su${ }^{1}$, Hui Feng ${ }^{1}$, Huixia Yang ${ }^{1 *}$ (D) and on behalf of the
} Gestational diabetes mellitus Prevalence Survey (GPS) study Group

\begin{abstract}
Background: Anaemia in pregnant women is a public health problem, especially in developing countries. The aim of this study was to assess the prevalence and related risk factors of anaemia during pregnancy in a large multicentre retrospective study $(n=44,002)$ and to determine the adverse pregnancy outcomes in women with or without anaemia.

Methods: The study is a secondary data analysis of a retrospective study named "Gestational diabetes mellitus Prevalence Survey (GPS) study in China". Structured questionnaires were used to collect socio-demographic characteristics, haemoglobin levels and pregnancy outcomes from all the participants. Anaemia in pregnancy is defined as haemoglobin $<110 \mathrm{~g} / \mathrm{L}$. We used SPSS software to assess the predictors of anaemia and associated adverse pregnancy outcomes.

Results: The overall prevalence of anaemia was $23.5 \%$. Maternal anaemia was significantly associated with maternal age $\geq 35$ years $(A O R=1.386)$, family per capita monthly income $<1000 C N Y(A O R=1.671)$, rural residence $(A O R=1.308)$ and pre-pregnancy $\mathrm{BMl}<18.5 \mathrm{~kg} / \mathrm{m}^{2}$ ( $A O R=1.237$ ). Adverse pregnancy outcomes, including $\mathrm{GDM}$, polyhydramnios, preterm birth, low birth weight $(<2500 \mathrm{~g})$, neonatal complications and NICU admission, increased significantly $(P<0.001)$ in those with anaemia than those without.

Conclusions: The results indicated that anaemia continues to be a severe health problem among pregnant women in China. Anaemia is associated with adverse pregnancy outcomes. Pregnant women should receive routine antenatal care and be given selective iron supplementation when appropriate.
\end{abstract}

Keywords: Anaemia, Pregnant women, Associated factors, Pregnancy outcomes, China

\section{Background}

Anaemia is defined as a condition in which haemoglobin $(\mathrm{Hb})$ level in the body is lower than normal, which results in a decreased oxygen-carrying capacity of red blood cells to tissues [1]. It affects all age groups, but pregnant women and children are more vulnerable. Stevens et al. [2] reported that the global prevalence of

\footnotetext{
* Correspondence: yanghuixia@bjmu.edu.cn

'Department of Obstetrics and Gynaecology, Peking University First Hospital,

Xi'anmen Street No.1, Xicheng District, Beijing 100034, China

Full list of author information is available at the end of the article
}

anaemia in non-pregnant women, pregnant women and children is 29,38 and $43 \%$, respectively.

According to the WHO guidelines, anaemia in pregnancy is defined as a haemoglobin level $<110 \mathrm{~g} / \mathrm{L}[3,4]$. The prevalence of anaemia is an important health indicator. A study in 2013 showed that anaemia is more prevalent in developing countries (43\%) than developed countries (9\%) [5]. Previous studies have reported that the prevalence of anaemia in pregnancy varies in women with different socio-economic conditions, lifestyles, or health-seeking behaviours across different cultures [6, 7].

(c) The Author(s). 2018 Open Access This article is distributed under the terms of the Creative Commons Attribution 4.0 International License (http://creativecommons.org/licenses/by/4.0/), which permits unrestricted use, distribution, and 
Anaemia is one of the most prevalent complications during pregnancy. It is commonly considered a risk factor for poor pregnancy outcomes and can result in complications that threaten the life of both mother and foetus, such as preterm birth [8], low birth weight [9], foetal impairment, and maternal and foetal deaths [10].

Physiologically, plasma volume expands by $25-80 \%$ of pre-pregnancy volumes between the second trimester and the middle of the third trimester of pregnancy [11, 12]. This induces a modest decrease in $\mathrm{Hb}$ levels during pregnancy. Previous studies show that the best time to investigate any risk factors associated with anaemia may be up until 20 weeks of gestation [13]. Thus, in this study, we took the haemoglobin level estimated before the 14th week of gestation to determine factors associated with anaemia in pregnant women. Considering the physiological changes in plasma volume, we used the third trimester's $\mathrm{Hb}$ level to assess the pregnancy outcomes of anaemia.

In the present study, associated factors, including sociodemographic factors, body mass index, parity and age were analysed, and we evaluated the maternal and foetal outcomes among anaemic and non-anaemic women.

\section{Methods}

\section{Data sources}

We conducted a large retrospective study entitled "Gestational diabetes mellitus Prevalence Survey in China (the GPS study)" in 21 hospitals, including 15 centres in Beijing, 5 centres in Guangzhou and 1 centre in Chengdu. Medical records of 44,002 pregnant women who delivered between June 2013 and May 2015 were collected. We designed a structured questionnaire to collect the socio-demographic, obstetric and medical history of pregnant women [14]. An additional file shows the questionnaire in more details (see Additional file 1). The GPS study aimed to investigate the prevalence of pregnancy diseases and the factors associated with the determined diseases.

\section{Study design and population}

The present analysis was based on data from the GPS study. We recorded the haemoglobin level of pregnant women in three trimesters. Excluding 599 cases that lacked haemoglobin values in either trimester, 43,403 pregnancies were included in the study. We demonstrated the current status of anaemia during pregnancy in China from three aspects, including the prevalence of anaemia, related risk factors and the relationship between anaemia and pregnancy outcomes.

\section{Prevalence of anaemia}

Since three trimesters' haemoglobin levels of pregnant women were recorded, we found that the diagnosis of anaemia should be made when the haemoglobin value in any trimester was lower than $110 \mathrm{~g} / \mathrm{L}$. Thus, 43,403 participants were included.

\section{Related risk factors}

To analyse the factors associated with anaemia, we selected the $\mathrm{Hb}$ value of the early trimesters as a subgroup, which included 26,924 pregnant women. Women with pre-pregnancy diabetes mellitus (PGDM), chronic hypertension and chronic renal disease were excluded.

\section{Anaemia and adverse pregnancy outcomes}

To evaluate the risk of adverse pregnancy outcomes in women with and without anaemia, we used the $\mathrm{Hb}$ value in the 3rd trimester, which included 41,569 women. Women with PGDM, twin or multiple pregnancies, chronic hypertension, or other foetal factors (foetal malformations, foetal death) were excluded. We analysed the maternal outcomes, including caesarean section, GDM, hypertension, premature rupture of membranes (PROM), foetal distress, placenta abruption, polyhydramnios, and oligohydramnios; and infant complications, such as preterm labour, low birth weight, neonatal complications and NICU admission.

\section{Definitions}

Based on WHO criteria, we defined anaemia in pregnancy as $\mathrm{Hb}<110 \mathrm{~g} / \mathrm{L}$. Mild, moderate and severe anaemia were defined as $\mathrm{Hb}$ measurements between 100 and $109 \mathrm{~g} / \mathrm{L}$, 70-79 $\mathrm{g} / \mathrm{L}$ and less than $70 \mathrm{~g} / \mathrm{L}$, respectively [3].

Gestational age was based on the number of days between the first day of an expectant mother's last menstrual period (LMP) and date of delivery and was expressed in the week after the LMP. The 1st, 2nd and 3rd trimester were defined as a gestational age less than 14 weeks, 14-27.9 weeks and 28-42 weeks, respectively. Body mass index (BMI) was divided into four groups based on WHO recommendations for Asian populations: underweight: $\mathrm{BMI}<18.5 \mathrm{~kg} / \mathrm{m}^{2}$, normal: $18.5-23.9 \mathrm{~kg} / \mathrm{m}^{2}$, overweight: $24-27.9 \mathrm{~kg} / \mathrm{m}^{2}$, and obesity: $\geq 28 \mathrm{~kg} / \mathrm{m}^{2}$ [15].

Definition of maternal and neonatal outcomes: macrosomia was defined as new-born birth weight $\geq 4000 \mathrm{~g}$, while new-born birth weight $<2500$ g represented low birth weight. Preterm birth is defined as the time of delivery between the 28 and $36^{+6}$ gestational weeks. GDM was diagnosed according to the Chinese $\mathrm{MOH}$ 2011 criteria [16], which recommend that the diagnosis should be made when any one of the following values is met or exceeded in the $75 \mathrm{~g}$ oral glucose tolerance test (75 g OGTT) at 24-28 weeks: $0 \mathrm{~h}$ (fasting), $5.1 \mathrm{mmol} / \mathrm{L}$; $1 \mathrm{~h}, 10.0 \mathrm{mmol} / \mathrm{L}$; and $2 \mathrm{~h}, 8.5 \mathrm{mmol} / \mathrm{L}$. Hypertensive disorders include preeclampsia, eclampsia, pregnancyinduced hypertension and haemolysis, elevated liver enzymes and low platelet syndrome (HELLP). 


\section{Statistical analysis}

Data were entered into EPI data version 3.1 and cleaned. Finally, data were analysed using SPSS software version 22.0 for Mac (Chicago, IL, USA). Data were summarized in tables and figures. Continuous variables were presented as the mean \pm standard deviations (SDs). Bivariate and multivariate logistic regression analyses were performed to adjust for potential confounding factors. Variables with $P$-value $\leq 0.25$ by the bivariate analysis were candidates for the multiple logistic regression model. The results of group comparisons of risk factors and pregnancy outcomes were expressed as ORs (95\% CIs) for categorical variables. The $P$-value was set at $<0.05$ for statistical significance.

\section{Results}

Prevalence of anaemia among pregnant women

We included 43,403 pregnant women in our study. The number of participants in the anaemia and non-anaemia groups was 10,199 and 33,204, respectively. The prevalence of anaemia in total was $23.5 \%(10,199 / 43,043)$. The maternal demographic characteristics are shown in Table 1 . Sorted by city, we found that the prevalence of anaemia in Beijing, Guangzhou and Chengdu was 19.3\%, $38.8 \%$ and $23.9 \%$, respectively (Fig. 1 ).

In this study, we collected the $\mathrm{Hb}$ value of three trimesters, and there were 26,924, 33,879 and 41,569 effective $\mathrm{Hb}$ values in the 1st, 2nd and 3rd trimester, respectively. We found that the mean $\mathrm{Hb}$ values in the three trimesters were $129.89 \pm 9.90 \mathrm{~g} / \mathrm{L}, 118.99 \pm 9.78 \mathrm{~g} /$ $\mathrm{L}$ and $121.21 \pm 12.62 \mathrm{~g} / \mathrm{L}$, respectively (Table 2 ). The prevalence of anaemia was higher in the 2nd trimester (14.7\%) and 3rd trimester (16.6\%) than in the 1st trimester $(2.7 \%)$ (Table 3$)$. The severity of anaemia in pregnancy is shown in Table 3. Few pregnant women suffered from severe anaemia, while most of the participants had mild and moderate anaemia.

Table 1 Maternal demographic characteristics. Data are expressed as the means \pm SDs or $n(\%)$

\begin{tabular}{|c|c|c|c|}
\hline Variables & Anaemic & Non-anaemic & Total \\
\hline Pregnant women & 10,199 (23.5\%) & 33,204 (76.5\%) & $43,403(100.0 \%)$ \\
\hline $\begin{array}{l}\text { Maternal age } \\
\text { (years) }\end{array}$ & $29.50 \pm 4.46$ & $29.80 \pm 4.19$ & $29.73 \pm 4.25$ \\
\hline Gravidity & $1.94 \pm 1.20$ & $1.85 \pm 1.13$ & $1.87 \pm 1.15$ \\
\hline Parity & $0.78 \pm 0.73$ & $0.59 \pm 0.67$ & $0.64 \pm 0.69$ \\
\hline $\begin{array}{l}\text { Pre-pregnancy } \\
\mathrm{BMI}\left(\mathrm{kg} / \mathrm{m}^{2}\right)\end{array}$ & $20.57 \pm 4.39$ & $21.31 \pm 4.41$ & $21.13 \pm 4.42$ \\
\hline $\begin{array}{l}\text { Pre-pregnancy } \\
\text { height }(\mathrm{cm})\end{array}$ & $54.00 \pm 8.38$ & $56.42 \pm 9.18$ & $55.85 \pm 9.06$ \\
\hline $\begin{array}{l}\text { Pre-pregnancy } \\
\text { weight }(\mathrm{kg})\end{array}$ & $160.48 \pm 4.96$ & $161.56 \pm 4.92$ & $161.30 \pm 4.95$ \\
\hline
\end{tabular}

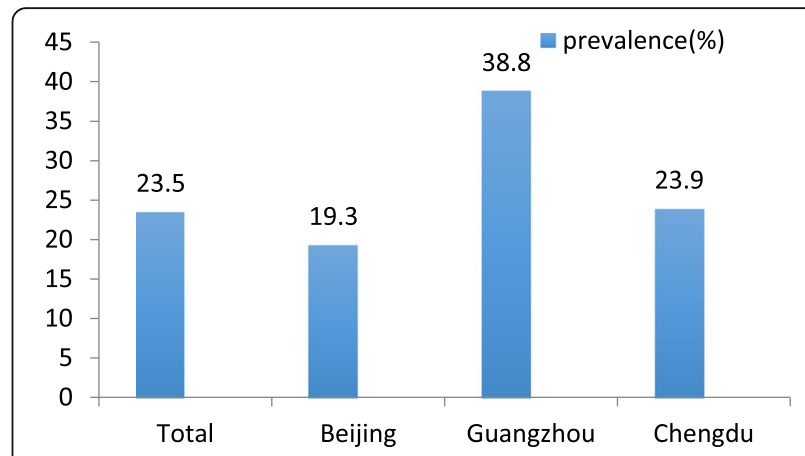

Fig. 1 Prevalence of anaemia in China

\section{Factors associated with anaemia}

A total of 26,255 women were included to evaluate the associated risk factors. Table 4 shows the maternal characteristics of the anaemia group versus the nonanaemia group. We found that the differences in maternal age, educational status, city, family monthly income, residence, pre-pregnancy BMI and parity were significant between anaemic and non-anaemic women (Table 5).

A binary logistic regression model was performed to identify the factors affecting maternal anaemia. After adjusted by other variables, maternal age $\geq$ 35 years $(\mathrm{AOR}=1.386,95 \% \mathrm{CI}: 1.103-1.742)$, women from Guangzhou (AOR = 7.293, 95\%CI:5.455-9.751) or Chengdu $(\mathrm{AOR}=2.147, \quad 95 \% \mathrm{CI}: 2.174-3.777)$, family per capita monthly income $<1000 \mathrm{CNY}(\mathrm{AOR}=1.671$, 95\%CI:1.2912.162), rural residence $(\mathrm{AOR}=1.308,95 \% \mathrm{CI}: 1.095-1.563)$ and pre-pregnancy $\mathrm{BMI}<18.5 \mathrm{~kg} / \mathrm{m}^{2} \quad(\mathrm{AOR}=1.237$, 95\%CI:1.021-1.498) were the predictors of anaemia among the pregnant women (Table 6).

\section{The risk of adverse pregnancy outcomes}

We enrolled 39,439 women with singleton pregnancies. Table 7 shows the maternal characteristics of the anaemia group and the non-anaemia group. We found that the prevalence of polyhydramnios, preterm birth, low birth weight $(<2500 \mathrm{~g})$, neonatal complications and NICU admission increased in the women with anaemia, while GDM, foetal distress and oligohydramnios increased in non-anaemic women (Table 8).

Table $2 \mathrm{Hb}$ level of three trimesters in pregnancy

\begin{tabular}{lllll}
\hline & Number & Percent & $\mathrm{Hb}(\mathrm{g} / \mathrm{L})$ & Testing time (week) \\
\hline 1st trimester & 26,924 & 61.2 & $129.89 \pm 9.90$ & $10.65 \pm 2.72$ \\
2nd trimester & 33,879 & 77.0 & $118.99 \pm 9.78$ & $23.17 \pm 3.39$ \\
3rd trimester & 41,569 & 94.5 & $121.21 \pm 12.62$ & $37.24 \pm 2.71$ \\
\hline
\end{tabular}


Table 3 Anaemia and its severity in three trimesters in pregnancy

\begin{tabular}{|c|c|c|c|c|c|c|c|c|c|}
\hline & \multirow{3}{*}{$\begin{array}{l}\text { Total } \\
\mathrm{N}\end{array}$} & \multirow{2}{*}{\multicolumn{2}{|c|}{ Anaemia }} & \multicolumn{6}{|c|}{ Severity of anaemia } \\
\hline & & & & \multicolumn{2}{|c|}{ Mild } & \multicolumn{2}{|c|}{ Moderate } & \multicolumn{2}{|c|}{ Severe } \\
\hline & & N & $\%$ & $N$ & $\%$ & $N$ & $\%$ & $N$ & $\%$ \\
\hline 1st trimester & 26,924 & 732 & 2.7 & 567 & 77.5 & 165 & 22.5 & 0 & - \\
\hline 2nd trimester & 33,879 & 4996 & 14.7 & 4144 & 82.9 & 848 & 17.0 & 4 & 0.1 \\
\hline 3rd trimester & 41,569 & 6888 & 16.6 & 5073 & 73.6 & 1800 & 26.1 & 15 & 0.2 \\
\hline
\end{tabular}

\section{Discussion}

Anaemia is one of the most common complications during pregnancy and could cause adverse pregnancy outcomes. It is a public health problem not only in developing but also in industrialized countries. In the present study, the overall prevalence of anaemia is $23.5 \%$. According to the WHO classification of the public health importance of anaemia [3], it was a moderate public health problem among the pregnant women in our study. However, compared to the prevalence of anaemia in developed countries [5], it remains a severe health problem in China.

To our knowledge, this study is the first to compare the prevalence of anaemia in three big cities, which may partially represent the Western, Northern and Southern China. We found that the prevalence of anaemia in Guangzhou (38.8\%) and Chengdu (23.9\%) was significantly higher than the total, while it was lower in Beijing (19.3\%). This prevalence was comparable to a study conducted in rural Western China (45.7\%) [17]. The results may have been due to the different levels of local economic development, lifestyle, and diet, and may also be related to the altitude of the area.

Our study showed that the prevalence of anaemia increased with the progress of pregnancy. We found that the anaemia prevalence gradually increased from early pregnancy $(2.7 \%)$ to middle pregnancy $(14.7 \%)$, then became the highest in late pregnancy (16.6\%). The change

Table 4 Maternal characteristics of the selected population. Data expressed as the means \pm SDs or $n(\%)$

\begin{tabular}{|c|c|c|c|}
\hline Variables & Anaemic & Non-anaemic & Total \\
\hline Haemoglobin (g/L) & $103.31 \pm 5.88$ & $130.55 \pm 8.89$ & $129.80 \pm 9.88$ \\
\hline $\begin{array}{l}\text { Gestation week } \\
\text { (weeks) }\end{array}$ & $11.32 \pm 2.38$ & $10.63 \pm 2.73$ & $10.65 \pm 2.72$ \\
\hline $\begin{array}{l}\text { Maternal age } \\
\text { (years) }\end{array}$ & $29.91 \pm 4.43$ & $30.02 \pm 3.93$ & $30.01 \pm 3.94$ \\
\hline Gravidity & $1.96 \pm 1.21$ & $1.77 \pm 1.09$ & $1.78 \pm 1.10$ \\
\hline Parity & $0.83 \pm 0.72$ & $0.51 \pm 0.63$ & $0.52 \pm 0.63$ \\
\hline $\begin{array}{l}\text { Pre-pregnancy } \\
\mathrm{BMI}\left(\mathrm{kg} / \mathrm{m}^{2}\right)\end{array}$ & $20.34 \pm 3.88$ & $21.23 \pm 4.13$ & $21.20 \pm 4.13$ \\
\hline $\begin{array}{l}\text { Pre-pregnancy } \\
\text { height }(\mathrm{cm})\end{array}$ & $160.45 \pm 4.67$ & $161.77 \pm 4.91$ & $161.74 \pm 4.91$ \\
\hline $\begin{array}{l}\text { Pre-pregnancy } \\
\text { weight (kg) }\end{array}$ & $53.00 \pm 7.64$ & $56.13 \pm 8.76$ & $56.05 \pm 8.75$ \\
\hline
\end{tabular}

Table 5 Clinical variables in association with anaemia among pregnant women [N (\%)]

\begin{tabular}{lllll}
\hline Variables & Anaemic & Non-anaemic & $x^{2}$ & $P$-value \\
\hline Pregnant women & $719(23.5 \%)$ & $25,536(76.5 \%)$ & & \\
Maternal age & & & & \\
$\quad<20 y$ & $5(8.2 \%)$ & $56(91.8 \%)$ & 15.424 & $<0.001^{*}$ \\
$20-35$ & $616(2.6 \%)$ & $22,850(97.4 \%)$ & & \\
$\geq 35$ & $98(3.6 \%)$ & $2630(96.4 \%)$ & & \\
Educational status & & & & \\
College and above & $485(2.3 \%)$ & $20,168(97.7 \%)$ & 69.346 & $<0.001^{*}$ \\
Junior or senior & $224(4.5)$ & $4748(95.5 \%)$ & & \\
Primary or illiteracy & $3(3.3 \%)$ & $88(96.7 \%)$ & & \\
Cities & & & & \\
Beijing & $296(1.6 \%)$ & $17,951(98.4 \%)$ & 477.503 & $<0.001^{*}$ \\
Guangzhou & $164(10.5 \%)$ & $1400(89.5 \%)$ & & \\
Chengdu & $259(4.0 \%)$ & $6185(96.0 \%)$ & &
\end{tabular}

Family per capita monthly income (CNY)

$\begin{array}{lllll}<1000 & 140(2.2 \%) & 6170(97.8 \%) & 9.256 & 0.010^{*} \\ 1000-4999 & 262(2.9 \%) & 8667(97.1 \%) & & \\ \geq 5000 & 308(2.9 \%) & 10,141(97.1 \%) & & \end{array}$

Residence

$\begin{array}{lllll}\text { Urban } & 487(2.4 \%) & 19,671(97.6 \%) & 36.801 & <0.001^{*} \\ \text { Rural } & 226(3.9 \%) & 5580(96.1 \%) & & \end{array}$

Pre-pregnancy BMI $\left(\mathrm{kg} / \mathrm{m}^{2}\right)$

$\begin{array}{lllll}<18.5 & 152(3.6 \%) & 4046(96.4 \%) & 35.163 & <0.001^{*} \\ 18.5-23.99 & 483(2.8 \%) & 17.737(97.2 \%) & & \\ 24-27.99 & 62(1.7 \%) & 3589(98.3 \%) & & \\ \geq 28 & 13(1.3 \%) & 980(98.7 \%) & & \\ \text { Parity } & & & & \\ 0 & 246(1.7 \%) & 14,316(98.3 \%) & 148.303 & <0.001^{*} \\ 1-3 & 463(4.0 \%) & 11,101(96.0 \%) & & \\ \geq 4 & 8(11.0 \%) & 65(89.0 \%) & & \end{array}$

The results are reported as the frequency (percentage) and $* P$-value $<0.05$ was statistically significant

in the haemoglobin level during the second trimester may be related to physiological changes during pregnancy, which is due to plasma dilution. In the third trimester, physiologically, the increased plasma volume velocity slows down and women may undergo routine antenatal care and iron supplementation, which will elevate the $\mathrm{Hb}$ level [18]. However, we found an increased prevalence in the third trimester, which may have been due to inadequate iron supplementation.

Considering the degree of anaemia, Desalegn et al. [19] reported that of 66 anaemic pregnant women, 40. $92 \%$ had mild, $54.54 \%$ had moderate, and $4.54 \%$ had severe anaemia. Another study showed that among 224 pregnant women, $37 \%$ women had anaemia ( $26 \%$ mild 
Table 6 Predictors of anaemia among pregnant women

\begin{tabular}{|c|c|c|c|c|c|c|}
\hline Variables & COR & $95 \% \mathrm{Cl}$ & $P$-value & AOR & $95 \% \mathrm{Cl}$ & $P$-value \\
\hline \multicolumn{7}{|l|}{ Maternal age } \\
\hline$<20 y$ & 3.312 & $1.322-8.297$ & $0.011^{*}$ & 2.489 & $0.958-6.467$ & 0.061 \\
\hline $20-35$ & 1 & & & 1 & & \\
\hline$\geq 35$ & 1.382 & $1.113-1.717$ & $0.003^{*}$ & 1.386 & $1.103-1.742$ & $0.005^{*}$ \\
\hline \multicolumn{7}{|l|}{ Educational status } \\
\hline College and above & 1 & & & - & & \\
\hline Junior or senior & 0.705 & $0.222-2.237$ & 0.553 & - & & \\
\hline Primary or illiteracy & 1.384 & $0.434-4.408$ & 0.583 & - & & \\
\hline \multicolumn{7}{|l|}{ Cities } \\
\hline Beijing & 1 & & & 1 & & \\
\hline Guangzhou & 7.104 & $5.826-8.663$ & $<0.001^{*}$ & 7.293 & $5.455-9.751$ & $<0.001^{*}$ \\
\hline Chengdu & 2.540 & $2.144-3.008$ & $<0.001^{*}$ & 2.847 & $2.147-3.777$ & $<0.001^{*}$ \\
\hline \multicolumn{7}{|c|}{ Family per capita monthly income (RMB, CYN) } \\
\hline$<1000$ & 0.747 & $0.610-0.915$ & $0.005^{*}$ & 1.671 & $1.291-2.162$ & $<0.001^{*}$ \\
\hline 1000-4999 & 0.995 & $0.842-1.176$ & 0.956 & 1.157 & $0.968-1.382$ & 0.109 \\
\hline$\geq 5000$ & 1 & & & 1 & & \\
\hline \multicolumn{7}{|l|}{ Residence } \\
\hline Urban & 1 & & & 1 & & \\
\hline Rural & 1.636 & $1.393-1.921$ & $<0.001^{*}$ & 1.308 & $1.095-1.563$ & $0.003^{*}$ \\
\hline \multicolumn{7}{|c|}{ Pre-pregnancy BMI (kg/m²) } \\
\hline$<18.5$ & 1.302 & $1.081-1.567$ & 0.005 & 1.237 & $1.021-1.498$ & $0.030^{*}$ \\
\hline $18.5-23.99$ & 1 & & & 1 & & \\
\hline $24-27.99$ & 0.599 & $0.458-0.782$ & $<0.001^{*}$ & 0.662 & $0.506-0.867$ & $0.003^{*}$ \\
\hline$\geq 28$ & 0.460 & $0.264-0.800$ & $0.006^{*}$ & 0.506 & 0.283-0.906 & $0.022^{*}$ \\
\hline \multicolumn{7}{|l|}{ Parity } \\
\hline 0 & 1 & & & 1 & & \\
\hline $1-3$ & 2.427 & $2.075-2.839$ & $<0.001^{*}$ & 1.071 & $0.842-1.363$ & 0.576 \\
\hline$\geq 4$ & 7.162 & $3.400-15.089$ & $<0.001^{*}$ & 2.130 & $0.920-4.932$ & 0.078 \\
\hline
\end{tabular}

COR Crude Odds Ratio, AOR Adjusted Odds Ratio, Cl Confidence interval

${ }^{*} P$-value $<0.05$ was statistically significant

Table 7 Maternal characteristics of the selected population. Data expressed as the means \pm SDs or $n$ (\%)

\begin{tabular}{llll}
\hline Variables & Anaemic & Non-anaemic & Total \\
\hline Pregnant women & $6476(16.4 \%)$ & $32,963(83.6 \%)$ & $39,439(100 \%)$ \\
Haemoglobin $(\mathrm{g} / \mathrm{L})$ & $102.16 \pm 6.64$ & $125.09 \pm 9.64$ & $121.32 \pm 12.53$ \\
Gestation week & $22.65 \pm 3.61$ & $23.25 \pm 3.36$ & $23.17 \pm 3.40$ \\
Maternal age (years) & $29.21 \pm 4.48$ & $29.74 \pm 4.18$ & $29.66 \pm 4.23$ \\
Gravidity & $1.99 \pm 1.21$ & $1.83 \pm 1.13$ & $1.86 \pm 1.14$ \\
Parity & $0.86 \pm 0.74$ & $0.59 \pm 0.67$ & $0.63 \pm 0.69$ \\
Pre-pregnancy BMl $\left(\mathrm{kg} / \mathrm{m}^{2}\right)$ & $20.48 \pm 4.51$ & $21.14 \pm 4.33$ & $21.04 \pm 4.36$ \\
Pre-pregnancy height $(\mathrm{cm})$ & $160.39 \pm 4.92$ & $161.48 \pm 4.92$ & $161.30 \pm 4.93$ \\
Pre-pregnancy weight $(\mathrm{kg})$ & $53.96 \pm 8.30$ & $55.93 \pm 8.89$ & $55.61 \pm 8.83$ \\
\hline
\end{tabular}


Table 8 Adverse pregnancy outcomes in anaemic and non-anaemic women. [N (\%)]

\begin{tabular}{|c|c|c|c|c|}
\hline Variables & Anaemic & Non-anaemic & $x^{2}$ & $P$ \\
\hline Caesarean section & $2986(46.1 \%)$ & $15,031(45.6 \%)$ & 0.565 & 0.452 \\
\hline GDM & $1031(15.9 \%)$ & $6575(19.9 \%)$ & 56.368 & $<0.001^{*}$ \\
\hline Hypertensive disorder & $165(2.5 \%)$ & $863(2.6 \%)$ & 0.105 & 0.746 \\
\hline PROM & $1319(20.4 \%)$ & $7021(21.3 \%)$ & 2.820 & 0.093 \\
\hline Foetal distress & $611(9.4 \%)$ & $4119(12.5 \%)$ & 48.049 & $<0.001^{*}$ \\
\hline Placenta abruption & $28(0.40)$ & $147(0.4 \%)$ & 0.23 & 0.880 \\
\hline Polyhydramnios & $125(1.95)$ & $386(1.2 \%)$ & 24.394 & $<0.001^{*}$ \\
\hline Oligohydramnios & $168(2.6 \%)$ & $1202(3.6 \%)$ & 17.876 & $<0.001^{*}$ \\
\hline Preterm labour & $529(8.2 \%)$ & $1600(4.9 \%)$ & 116.45 & $<0.001^{*}$ \\
\hline Low birth weight $(<2500 \mathrm{~g})$ & $319(4.9 \%)$ & $1108(3.4 \%)$ & 37.991 & $<0.001^{*}$ \\
\hline Neonatal complications & $687(10.6 \%)$ & $2501(7.6 \%)$ & 66.489 & $<0.001^{*}$ \\
\hline NICU admission & $631(9.7 \%)$ & $2000(6.1 \%)$ & 117.492 & $<0.001^{*}$ \\
\hline
\end{tabular}

${ }^{\bar{*} P}<0.05$ is statistically significant

and $11 \%$ moderate). Our results showed findings similar to those studies.

The results of our study showed that pregnant women with lower family per capita income were more anaemic than the higher one. The higher prevalence of anaemia was also found among pregnant women from rural areas. The results of a study in Pakistan showed that patients with low income comprised a higher portion of patients with anaemia compared to those with a high income [20]. This is likely related to the lack of information about adequate nutrition during pregnancy, economic factors and the inaccessibility of health care centres. Interestingly, our study also indicated that pre-pregnancy BMI $<18.5 \mathrm{~kg} / \mathrm{m}^{2}$ was a predictor of anaemia, which may be due to the inadequate nutrition during pregnancy. Previous studies have shown an association of anaemia with low education status [5, 21] and multiparity [22]. However, we did not find this association in our study. This might have been due to variations in the methods and study subjects involved. These predictors of anaemia (including age, income, area, pre-pregnancy BMI) may provide clinical guidance. Women with these risk factors should appropriately increase their nutrition during pregnancy, and pregnant women diagnosed with anaemia should take iron supplements.

It has been suggested that anaemia in pregnancy is associated with an increased risk of adverse pregnancy outcomes, such as preterm birth, hypertensive disorders, and low birth weight [13, 23, 24]. Preterm labour and low birth weight have been reported to be suboptimal pregnancy outcomes of anaemia in previous studies [8, 25, 26]. These results were in accordance with our findings. We also found that an increase of NICU admission in anaemic women. This may be due to the higher prevalence of preterm birth and low birth weight in anaemic women than non-anaemic women.

The association between GDM and anaemia has not been well reported. In our study, we observed that anaemia reduced the prevalence of GDM. Lao et al. [27] reported that the prevalence of GDM is reduced in iron deficiency anaemia. These results indicate that haemoglobin level is positively associated with the prevalence of GDM. Our study also first reported that anaemia is associated with polyhydramnios, which may occur in parallel with the GDM outcome.

Although the sample size and the study sites included 21 centres in China, there may be bias in our results, as the data were collected in a retrospective manner. Studies reported that the inter pregnancy interval [22] and history of parasitic infection [7, 28] were associated with the prevalence of anemia, which could not be estimated in this study due to the lake of the factors. Recent studies noted that both low and high iron intake was associated with mortality among women [29] and elevated iron level may increase the risk of GDM [30]. However, the present study did not record the iron supplementation of the participants, which may have impacted the results of adverse pregnancy outcomes of anaemia.

\section{Conclusion}

This study showed that anaemia in pregnancy continues to be a health problem in China, and economic factors may contribute to the situation. Therefore, we should vigorously promote early prenatal care for these at-risk pregnant women. This would allow for iron and folic acid supplementation during pregnancy, which would potentially reduce the prevalence of anaemia. 


\section{Additional file}

Additional file 1: Questionnaire. (DOCX $104 \mathrm{~kb}$ )

\begin{abstract}
Abbreviations
$75 \mathrm{~g}$ OGTT: $75 \mathrm{~g}$ oral glucose tolerance test; AOR: Adjusted odds ratio; BMI: Body mass index; Cl: Confidence interval; CNY: China Yuan; COR: Crude odds ratio; GDM: Gestational diabetes mellitus; GPS study: Gestational diabetes mellitus Prevalence Survey study; Hb: Haemoglobin; HELLP syndrome: Haemolysis, elevated liver enzymes and low platelet syndrome; LMP: Last menstrual period; NICU: Neonatal Intensive Care Unit; OR: Odds ratio; PGDM: Pre-pregnancy diabetes mellitus; PROM: Premature rupture of membranes; SD: Standard deviation
\end{abstract}

\section{Acknowledgements}

We appreciate all the investigators' efforts in data collection. We acknowledge and thank the GPS study group for providing medical records from the 21 hospitals.

\section{Funding}

The study was supported by the World Diabetes Foundation (Grant no. WDF10-517) and (Grant no. WDF14-908), Beijing Municipal Science and Technology Project (Z151100001615051) and National Key Technology Research and Development Program of China (2015BAl13B06). These funding bodies accepted the study as proposed and played roles in protocol development, data collection, analysis and manuscript writing.

\section{Availability of data and materials}

The datasets used and analysed during the current study are available from the corresponding author on reasonable request.

\section{Authors' contributions}

LL collected the data, conducted the data analysis and prepared the manuscript; HY, YW and WZ contributed to the design and analysis of the study; and CW, RS and HF were involved in the collection of the data. All authors have read and approved the final version of the manuscript.

\section{Ethics approval and consent to participate}

This study was reviewed and approved by the Institutional Review Boards of the Peking University First Hospital (reference number: 2013[578]). All participants provided written informed consent, and the ethics committee approved the procedures.

\section{Competing interests}

The authors declare that they have no competing interests.

\section{Publisher's Note}

Springer Nature remains neutral with regard to jurisdictional claims in published maps and institutional affiliations.

\section{Author details}

${ }^{1}$ Department of Obstetrics and Gynaecology, Peking University First Hospital, Xi'anmen Street No.1, Xicheng District, Beijing 100034, China. ${ }^{2}$ National Institute of Hospital Administration, Beijing 100191, China.

\section{Received: 28 March 2017 Accepted: 10 April 2018}

\section{Published online: 23 April 2018}

\section{References}

1. Grewal A. Anaemia and pregnancy: Anaesthetic implications. Indian J Anaesth. 2010;54(5):380-6.

2. Stevens GA, Finucane MM, De-Regil LM, Paciorek CJ, Flaxman SR, Branca F, et al. Global, regional, and national trends in haemoglobin concentration and prevalence of total and severe anaemia in children and pregnant and non-pregnant women for 1995-2011: a systematic analysis of populationrepresentative data. Lancet Glob Health. 2013;1(1):e16-25.

3. WHO. Haemoglobin concentrations for the diagnosis of anaemia and assessment of severity. Edited by World Health Organization. 2011 Available online from: http://apps.who.int/iris/bitstream/10665/85839/3/WHO_NMH_ NHD_MNM 11.1_eng.pdf.

4. World Health Organization. Worldwide prevalence of anaemia 1993-2005: WHO global database on anaemia. Edited by Bruno de Benoist, Erin McLean, Ines Egli and Mary Cogswell. 2008 Available online from: http:// apps.who.int/iris/bitstream/10665/43894/1/9789241596657_eng.pdf.

5. Balarajan Y, Ramakrishnan U, Ozaltin E, Shankar AH, Subramanian SV. Anaemia in low-income and middle-income countries. Lancet. 2011; 378(9809):2123-35.

6. Gebre A, Mulugeta A. Prevalence of anemia and associated factors among pregnant women in north western zone of Tigray, Northern Ethiopia: a cross-sectional study. J Nutr Metab. 2015;2015:165430.

7. Kefiyalew F, Zemene E, Asres Y, Gedefaw L. Anemia among pregnant women in Southeast Ethiopia: prevalence, severity and associated risk factors. BMC Res Notes. 2014:7:771

8. Levy A, Fraser D, Katz M, Mazor M, Sheiner E. Maternal anemia during pregnancy is an independent risk factor for low birthweight and preterm delivery. Eur J Obstet Gynecol Reprod Biol. 2005;122(2):182-6.

9. Banhidy F, Acs N, Puho EH, Czeizel AE. Iron deficiency anemia: pregnancy outcomes with or without iron supplementation. Nutrition. 2011;27(1):65-72.

10. Haas JD, Brownlie T. Iron deficiency and reduced work capacity: a critical review of the research to determine a causal relationship. J Nutr. 2001; 131(2S-2):676S-88S. discussion 688S-690S

11. Chesley LC. Plasma and red cell volumes during pregnancy. Am J Obstet Gynecol. 1972;112(3):440-50

12. Goodlin RC. Maternal plasma volume and disorders of pregnancy. Br Med J (Clin Res Ed). 1984;288(6428):1454-5.

13. Haider BA, Olofin I, Wang M, Spiegelman D, Ezzati M, Fawzi WW. Anaemia, prenatal iron use, and risk of adverse pregnancy outcomes: systematic review and meta-analysis. BMJ. 2013;f3443:346

14. Wang C, Zhu W, Wei Y, Su R, Feng $H$, Lin $L$, et al. The predictive effects of early pregnancy lipid profiles and fasting glucose on the risk of gestational diabetes mellitus stratified by body mass index. J Diabetes Res. 2016;2016: 3013567.

15. WHO Expert Consultation. Appropriate body-mass index for Asian populations and its implications for policy and intervention strategies. Lancet. 2004;363(9403):157-63.

16. Yang HX. Diagnostic criteria for gestational diabetes mellitus (WS 331-2011). Chin Med J. 2012;125(7):1212-3.

17. Pei L, Ren L, Wang D, Yan H. Assessment of maternal anemia in rural Western China between 2001 and 2005: a two-level logistic regression approach. BMC Public Health. 2013;13:366.

18. Scholl TO. Iron status during pregnancy: setting the stage for mother and infant. Am J Clin Nutr. 2005:81(5):1218s-22s.

19. Desalegn S. Prevalence of anaemia in pregnancy in Jima town, southwestern Ethiopia. Ethio Med J. 1993:31(4):251-8.

20. Ayub R, Tariq N, Adil MM, Iqbal M, Jaferry T, Rais SR. Low haemoglobin levels, its determinants and associated features among pregnant women in Islamabad and surrounding region. J Pak Med Assoc. 2009;59(2):86-9.

21. Chowdhury HA, Ahmed KR, Jebunessa F, Akter J, Hossain S, Shahjahan M. Factors associated with maternal anaemia among pregnant women in Dhaka city. BMC Womens Health. 2015;15:77.

22. Obse N, Mossie A, Gobena T. Magnitude of anemia and associated risk factors among pregnant women attending antenatal care in Shalla Woreda, West Arsi Zone, Oromia Region, Ethiopia. Ethio J Health Sci. 2013;23(2):165-73

23. Xiong $X$, Buekens $P$, Alexander S, Demianczuk N, Wollast E. Anemia during pregnancy and birth outcome: a meta-analysis. Am J Perinatol. 2000;17(3):137-46.

24. Pena-Rosas JP, De-Regil LM, Garcia-Casal MN, Dowswell T. Daily oral iron supplementation during pregnancy. Cochrane Database Syst Rev. 2015;7: CD004736.

25. Malhotra M, Sharma JB, Batra S, Sharma S, Murthy NS, Arora R. Maternal and perinatal outcome in varying degrees of anemia. Int J Gynaecol Obstet. 2002;79(2):93-100.

26. Scholl TO, Hediger ML, Fischer RL, Shearer JW. Anemia vs iron deficiency: increased risk of preterm delivery in a prospective study. Am J Clin Nutr. 1992;55(5):985-8.

27. Lao $\Pi, \mathrm{Ho}$ LF. Impact of iron deficiency anemia on prevalence of gestational diabetes mellitus. Diabetes Care. 2004;27(3):650-6. 
28. Getachew M, Yewhalaw D, Tafess K, Getachew Y, Zeynudin A. Anaemia and associated risk factors among pregnant women in Gilgel Gibe dam area, Southwest Ethiopia. Parasit Vectors. 2012;5:296.

29. Shi Z, Zhen S, Zhou Y, Taylor AW. Hb level, iron intake and mortality in Chinese adults: a 10-year follow-up study. Br J Nutr. 2017;117(4):572-81.

30. Rawal S, Hinkle SN, Bao W, Zhu Y, Grewal J, Albert PS, et al. A longitudinal study of iron status during pregnancy and the risk of gestational diabetes: findings from a prospective, multiracial cohort. Diabetologia. 2017;60(2):249-57.

Ready to submit your research? Choose BMC and benefit from:

- fast, convenient online submission

- thorough peer review by experienced researchers in your field

- rapid publication on acceptance

- support for research data, including large and complex data types

- gold Open Access which fosters wider collaboration and increased citations

- maximum visibility for your research: over $100 \mathrm{M}$ website views per year 